\title{
Formation of the intercultural competence of pupils in the conditions of high school
}

\begin{abstract}
The article discusses the formation of intercultural competence in school; we discuss different aspects of the school environment, which may affect the adoption by students of ethnic diversity. Intercultural competence is understood as the value attitude to the culture and history of other peoples, the pursuit of inter-ethnic harmony. The analysis of the federal state educational standards and programs in the field of formation of intercultural competence of students. The productivity of the formation of intercultural competence of students associated with the introduction of multicultural education, which is to recognize students for cultural diversity as a social norms and personal values. As the most influential agents in the school textbook and the teacher are allocated. Discussion of ethnic differences in modern school textbooks has a number of risks: the language confusing, redundant and makes calls for tolerance towards others in abstract moralizing and unconvincing statements. Teachers do not always take into account the ethnic and cultural features of learning and communication students.
\end{abstract}

Keywords: intercultural competence, high school students
Volume 9 Issue 6 - 2018

\author{
Soelma Dagbaevaa \\ Department of Psychology, Zabaikal State University, Russia
}

Correspondence: Soelma Dagbaevaa, Department of Psychology, Faculty of Psychology and Pedagogics, Zabaikal State University, Russia, Email soela@bk.ru

Received: September II, 2018 | Published: December 19, 2018

\section{Introduction}

Today, more and more urgent it becomes the problem of multiculturalism in the school. Actively discussed the role of parents, teachers and peers in shaping intercultural competences. ${ }^{1}$ The modern school there is a tendency reducing the number of homogeneous classes and the emergence of multi-ethnic classes. ${ }^{2}$ However, technologies of forming cross-cultural competence in general education remain insufficiently developed. ${ }^{3,4}$ Education refers to the conservative innovations, but, nevertheless, in connection with the modernization of actively penetrating strong changes observed in this area. ${ }^{5}$ Education ceases to be only a stage in the beginning of life and becomes a continuous process that accompanies a person throughout life. At the same time the demand for multicultural and multilingual identity will only increase [ibid]. Thus, the new realities require educational organization that promotes human integration in multiethnic world as an active figure. ${ }^{6}$ Today the formation of intercultural competence and mutual respect in the minds of people - not just the task of education, and its main function.

\section{Objectives, methodology and research design}

The object of study: features of formation of intercultural competence of high school students in modern conditions. The research methodology is based on the provisions of postnonclassical educational psychology, basic postulate of which is to create the most favorable conditions possible in order to reveal the inner potential of each of the participants in the educational process. Logic studies include: an analysis of foreign and domestic traditions, federal state educational standards and programs in the field of formation of intercultural competence of students; identifying features.

\section{Discussion of the research outcomes}

The idea of integration and systematization of the universally recognized Russian traditions and values, understanding of national and national peculiarities of our country laid down in the new federal state educational standards. ${ }^{7}$ The new federal state educational standard of general education is based on a systemactivity approach, according to which the child's development occurs through pedagogically structured cooperation subjects of education by modeling an integrated system of education and socialization of students and through his activity. ${ }^{8}$ Vectors of intercultural competence school education program sets exemplary and socialization of primary, secondary and high schools. ${ }^{9-11}$ The strategic objective of the Program is to ensure that the conditions of spiritual and moral formation of the individual student, his civil identity, the active creative position, as well as preparation for vital self-determination in the subsequent development of their basic national values, the values of Russian society, human values and translate them into social practice. Addressing the formation of intercultural competence of students was also reflected in the draft of the Concept of development of multicultural education ${ }^{12}$ and the Integrated Program for the Development of Multicultural Education. ${ }^{13}$ Multicultural education is presented as an institution of socialization of the students focused, designed to contribute to the successful development of the cultural, historical and social experience of mankind, samples and values native, Russian and world culture; development of tolerance towards other peoples and cultures, susceptibility to cross-cultural communication and exchange; development of skills to articulate their views and argue make judgments, to articulate their own attitude to the events and phenomena; active interaction with different cultures while preserving its own language and cultural competence; the formation of a harmonious Russian identity on the basis of ethno-cultural and national-territorial identity [ibid]. Different models of multicultural education are the basis of the formation of civic identity of students and pupils in many modern multicultural societies. ${ }^{14}$

Multicultural education fosters a positive attitude to the presence in society of different ethnic and cultural groups and their ability to understand and interact with representatives of partners from other 
cultures. ${ }^{15}$ The most influential agents of socialization in school is the teacher and textbook. On how permeated by stereotypes and prejudices educational texts, sayings and actions of teachers, largely depends on the willingness of students to accept diversity of the world, their ability to recognize the right of the "other" to be different, and their responsibility for the reproduction of social inequality and discrimination. The presence in the educational and methodical literature, ethnocentrism, a modern version of racism not only promotes their widespread assimilation, but also supports the belief that alternatives to this vision of social relations do not exist. ${ }^{16}$ Textbooks continue to be the most common type of socializing texts under the control of the state, which allows us to consider the content as one of the embodiments of the state of identity politics. Textbooks study showed that, in the Russian school textbooks do not attempts to critically reflect on the experience of "the development of the national borderlands" and get rid of the paternalistic view of the "neighbors". Russian and Soviet presence on the territory of modern independent states is seen as a benefit to their peoples. Respectively, expressed "neighbors' claims cannot be understood as" fair ", having under itself any reason, within the existing formation of national histories of logic conflicts are intractable. ${ }^{17}$ Modern negotiable ethnic differences in textbooks is extremely problematic region. ${ }^{18}$ The dominant way of textbooks discuss the "national", in particular, involves the use of the concept of "ethnicity" as "historically established in a particular area community" that promotes the materialisation of symbolic boundaries and the reification of "culture"; It connects the "national culture" with "territories"; human attributes to "its national ethnic culture" and, accordingly, to a certain "territory" [ibid, p. 86]. Unfortunately, teachers do not always take into account culturally conditioned characteristics of learning and communication students. There may be situations when coupled with knowledge transfer educators broadcast inflexible, rigid and do not conform to the present time stereotypes, attitudes, beliefs, and methods of interaction with the world. Khukhlaeva $\mathrm{OV}^{19}$ identifies in problems including ethnopsychological teachers:

1. The action of the teacher biases negative evaluation pupil caused by it owing to the presence ethnicity particular installation against members of a particular ethnic group.

2. Lack of attention to the characteristics of the national character pupil.

3. Lack of understanding of the teacher culturally defined features verbal and nonverbal communication;

4. Lack of knowledge of the differences in the system of mental reflection and perception.

Due to the high probability of occurrence of these manifestations in a multicultural classroom need of emotional sensitivity and flexibility of the teacher, taking into account the specifics of the students of communication. Children who do not belong to the main cultural group, are more likely than others, may fall into a risk group in terms of performance due to differences in the preferred system of mental reflection and perception. The situation can contribute to failure of the appearance inferiority complex compensatory aggressiveness. ${ }^{20}$ And the inability and unwillingness of teachers to recognize the equivalence of cultures, whose representatives are trained in the educational institutions, may aggravate the situation.

\section{Conclusion}

Thus, we can formulate the following conclusions:

1. High school is an important institution, the necessary capacity for the formation of intercultural competence of pupils. Education should be involved in the formation of civil, ethno-cultural and universal identity, broadcast different traditions, values, norms and behavior of the younger generation plants, which requires changes in the system of relations within the educational space and expansion of children's learning process, the creation of extra-curricular structures, new educational forms, including rearrangement additional education, etc.

2. Ideas and directions of formation of intercultural competence laid down in the new GEF project of the state program of education and socialization of children in the project of multicultural education in the Russian Federation. The role of multicultural education consists in the construction of knowledge about society and ethno-cultural world, recognizing the cultural diversity of the students as the norms and values.

3. The most influential agents in the school are the teachers and textbooks, prepodnosyaschie knowledge as normative, requiring assimilation, which largely determines the willingness of students to accept ethnic and cultural diversity of the world. Relevant disciplines in ethnic socialization are history, social studies, the foundations of religious culture and secular ethics, translating basic national values and normative behavior. It must be admitted that the Russian teacher does not always take into account the ethnic and cultural characteristics of students, often broadcasts its negative ethnic stereotypes and attitudes that actualizes the issues of increasing their intercultural competence.

\section{Acknowledgment}

None.

\section{Conflicts of interest}

The author declares that there is no conflict of interest.

\section{References}

1. Thijs J, Verkuyten M. Multiculturalism in the classroom: Ethnic attitudes and classmates beliefs. International Journal of Intercultural Relations. 2013;37(2):176-187.

2. Fedorov SN. Ethnic and cultural development of children. Psychological and educational support: Textbook. 2011.

3. Berry John. Cross-cultural psychology. Research and application. 2007.

4. Zinurova RI. Ethnic socialization of youth in the conditions of a modern Russian society: Doctor: Sociology. 2005.

5. Luksha P, Luksha K, Sands D. Strategic Initiatives Agency under the President of the Russian Federation; The Moscow School of Management. 2014.

6. Feldstein DI. Problems of psychological and pedagogical sciences in spatial-temporal situation XXI century: challenges of the information age/DI Feldstein. Questions of psychology. 2013;1:46-65 
7. Darmodehin SV. The development of education and socialization of children as the strategic priorities of the modern educational system. 2013.

8. Asmolov, Volodarskaya I, Salmin N. Cultural-historical paradigm of system-activity standards for the design of school education. Questions of psychology. 2007;4:16-23.

9. Approximate program of education and socialization of students in primary schools. 2011.

10. Approximate program of education and socialization of primary school pupils. 2011.

11. Approximate program of education and socialization of students of high school. 2011

12. Draft concept of multicultural education in the Russian Federation. 2012.

13. A comprehensive program for the development of multicultural education. 2012.
14. Khakimov ER. Construction of multicultural education practices based on multiparadigmatic approach: abstract. 2012.

15. Stefanenko TG. Ethnopsychology: Workshop. Moscow: Aspekt Press;2006:208

16. Voronkov V, Karpenka O. Difficult not be racist (instead of the administration). 2008

17. Karpenko OV. Experience of the comparative analysis of textbooks. Instrumentalization of historical narratives. 2013.

18. Karpenko OV. Education "national" differences "people" in the textbooks of social science. 2008:47-87.

19. Khukhlaeva OV. Psychological "barriers" of interaction of teachers with students in a multicultural classroom. Practical ethnopsychology: actual problems and perspectives of development. 2008.

20. Khukhlaeva OV, Chibisova MY. Psychologist working in a multinational school: Textbook; 2011. 